\title{
COVID-19 and Policy Responses by International Organizations: Crisis of Liberal International Order or Window of Opportunity?
}

Citation for published version (APA):

Debre, M., \& Dijkstra, H. (2021). COVID-19 and Policy Responses by International Organizations: Crisis of Liberal International Order or Window of Opportunity? Global Policy, 12(4), 443-454. https://doi.org/10.1111/1758-5899.12975

Document status and date:

Published: 01/09/2021

DOI:

10.1111/1758-5899.12975

Document Version:

Publisher's PDF, also known as Version of record

Document license:

CC BY

Please check the document version of this publication:

- A submitted manuscript is the version of the article upon submission and before peer-review. There can be important differences between the submitted version and the official published version of record.

People interested in the research are advised to contact the author for the final version of the publication, or visit the DOI to the publisher's website.

- The final author version and the galley proof are versions of the publication after peer review.

- The final published version features the final layout of the paper including the volume, issue and page numbers.

Link to publication

\footnotetext{
General rights rights.

- You may freely distribute the URL identifying the publication in the public portal. please follow below link for the End User Agreement:

www.umlib.nl/taverne-license

Take down policy

If you believe that this document breaches copyright please contact us at:

repository@maastrichtuniversity.nl

providing details and we will investigate your claim.
}

Copyright and moral rights for the publications made accessible in the public portal are retained by the authors and/or other copyright owners and it is a condition of accessing publications that users recognise and abide by the legal requirements associated with these

- Users may download and print one copy of any publication from the public portal for the purpose of private study or research.

- You may not further distribute the material or use it for any profit-making activity or commercial gain

If the publication is distributed under the terms of Article $25 \mathrm{fa}$ of the Dutch Copyright Act, indicated by the "Taverne" license above, 


\title{
COVID-19 and Policy Responses by International Organizations: Crisis of Liberal International Order or Window of Opportunity?
}

\author{
Maria Josepha Debre (i) \\ University of Potsdam \\ Hylke Dijkstra (iD \\ Maastricht University
}

\section{Abstract}

The liberal international order is being challenged and international organizations (IOs) are a main target of contestation. COVID-19 seems to exacerbate the situation with many states pursuing domestic strategies at the expense of multilateral cooperation. At the same time, IOs have traditionally benefited from cross-border crises. This article analyzes the policy responses of IOs to the exogenous COVID-19 shock by asking why some IOs use this crisis as an opportunity to expand their scope and policy instruments? It provides a cross-sectional analysis using original data on the responses of 75 IOs to COVID19 during the first wave between March and June 2020. It finds that the bureaucratic capacity of IOs is significant when it comes to using the crisis as an opportunity. It also finds some evidence that the number of COVID-19 cases among the member states affects policy responses and that general purpose IOs have benefited more.

\section{Policy Implications}

- International organizations have responded very differently to COVID-19. Evidence from 75 international organizations shows that those with broad policy objectives have further expanded their scope and instruments. International organizations with a narrow focus have stuck to existing instruments.

- Bureaucratic capacity explains the ability of international organizations to use crises as an opportunity for institutional development. It is imperative that member states further invest in the bureaucratic capacity of international organizations, particularly in professional staff, to handle future crises.

- When considering future reforms of international organizations, member states should focus on strengthening the competences of the executive bodies to initiate policy to help organizations work better during crises.

- As we exit the pandemic it is tempting to concentrate on domestic affairs, including revisiting healthcare and pandemic response systems, but policy makers are advised to further develop global governance in these areas as well. While COVID-19 was initially seen as a major challenge to the liberal international order, it may well result in a deepening of global governance in the longer term.

\section{At a critical juncture}

The liberal international order is in crisis and international organizations (IOs) are a main target of contestation. ${ }^{1}$ Increasing politicization in combination with member states cutting resources, withdrawing from institutions, or setting up alternative venues for cooperation has impacted IOs in profound ways (e.g. von Borzykowski and Vabulas, 2019; Hale et al., 2013; Patz and Goetz, 2019; Zürn, 2018). The exogenous shock of COVID-19 has further exacerbated pressures with many states pursuing domestic strategies at the expense of multilateral cooperation. Academics and pundits have therefore been quick to characterize COVID-19 as yet another blow to the liberal international order (e.g. Kahl and Wright, 2021; Kenwick and Simmons, 2020; Mahbubani,
2020; Norrlöf, 2020a, 2020b). At the same time, we know that IOs are often created exactly to address cross-border problems (e.g. Rittberger et al., 2019) and that they regularly benefit from crises (Kreuder-Sonnen, 2019; Monnet, 1978; Olsson and Verbeek, 2018; Schimmelfennig, 2018).

This article analyzes the policy responses of 75 major IOs in the context of the exogenous COVID-19 shock by asking why some IOs use this crisis as an opportunity to expand their scope and policy instruments, whereas other IOs use existing instruments or barely engage with COVID-19 at all? The purpose is not to assess the effectiveness of IOs, but rather to examine whether IOs proactively used this exogenous shock as an opportunity to expand their activities during the first wave between March and June 2020. Even though the COVID-19 crisis continues to date, we assume 
that the initial responses of IOs were essential because critical junctures are brief moments in time and future developments with regard to legalization of policy expansions are likely path dependent on these initial responses (Gerschewski, 2021; Pierson, 2000). There are also first-mover advantages that affect how global governance gets reordered.

In line with research on international public administration, this article shows that the bureaucratic capacity of IOs is significant when it comes to providing continuity of operations and using the crisis as an opportunity: IOs with large secretariats are more likely to expand their scope and policy instruments in response to COVID-19. Such IOs may be able to reassign staff to work on crisis response, are more likely to have relevant in-house expertise, and can put forward policy proposals. We also find some evidence that IOs with delegated agenda-setting authority are better at using the crisis as an opportunity. While the operations of most IOs are affected by COVID-19, we also control for differences between IOs with regard their likelihood to respond to the crisis. We find, in this respect, that general purpose IOs are more likely to expand their scope and instruments compared to task-specific IOs (cf. Hooghe et al., 2019). We also find some evidence that the number of COVID-19 cases among 10 members helps to explain 10 responses. We do not find, however, that IOs with mandates in heavily affected policy fields such as health, trade, and border management are more likely to expand.

The article first conceptualizes policy responses of IOs and maps how 75 major IOs varied in trying to expand their scope and policy instruments during the initial crisis months from March until the end of the study period in June 2020. It then derives two sets of institutional hypotheses to explain observed variation in policy responses, discusses research design, and operationalizes the variables. The empirical section provides an ordered logit model that tests all hypotheses and shows the significance of large secretariats in explaining the expansion of scope and policy instruments. The article concludes by reflecting on the consequences of these findings for the state of the liberal international order.

\section{Policy responses by IOs during COVID-19}

Crises are commonly considered important moments in organizational history because they offer opportunities to change organizational processes (Boin et al., 2016). Punctuated equilibrium theory (PET), in particular, focuses on institutional change as a result of an exogenous shock with a short-term time horizon (Gerschewski, 2021). This makes COVID-19 an excellent test case, since it is clearly exogenous and required an immediate response by many IOs. COVID19 will, of course, also have longer-term consequences. Yet in the short-term, exogenous shocks have the potential to set institutions on a new track, or can also simply represent opportunities to change direction and branch out from an original path (Gerschewski, 2021; see also on PET: Baumgartner and Jones, 1993, Colgan et al., 2012; Lundgren et al.,
2018). Thus, choices made by IOs, during the brief initial window after COVID-19 was declared a pandemic in March 2020, can induce self-reinforcing processes and canalize future developments down a new path. IOs may also benefit from first-mover advantages in a crowed global governance landscape. Conversely, if IOs did not act during the first wave, they have little to build on to induce a long-term process of institutional change.

We are thus interested in institutional change as a result of COVID-19 and not policy effectiveness. We understand therefore the concept of policy response as any measure taken up by an 10 bureaucracy to deal with the pandemic. We are particularly interested whether this has resulted in proposals for an expanded scope of action and/or new policy instruments (Hooghe et al., 2019; Koremenos et al., 2001, 2001). Thus, policy responses encompass both the tasks performed by the institution, including in new policy areas, as well as employed instruments such as funding mechanisms, coordination tools, databases, research lines, or training programs. Our concept does not, however, cover policies that IOs have taken up to manage their internal operations such as regulations on remote work.

To give an example, the European Commission has negotiated collective agreements with pharmaceutical companies on vaccines. The European Union has furthermore agreed to a $100 \mathrm{bln}$ euro temporary unemployment scheme. It has also made available existing policy instruments such as the European Stability Mechanism for health purposes and has agreed to a new $750 \mathrm{bln}$ euro recovery fund financed through joint debt. In other words, the EU has clearly increased its policy scope into the areas of health and social policy while using existing and newly developed policy instruments (see Brooks and Geyer, 2020; Ladi and Tsarouhas, 2020; Wolff and Ladi, 2020). The World Trade Organization (WTO), on the other hand, only offered some updates on trade statistics in response to the pandemic. Even though it remains the focal institution for world trade, which was heavily affected by COVID-19, it thus did not expand its policy scope nor did it develop new policy instruments.

IO responses during the first wave of the COVID-19 crisis can be divided into three categories. First, some IOs essentially shut down or merely issued declaratory statements without really responding to COVID-19. Second, some IOs managed to perform their established tasks with existing instruments. Third, some IOs were able to take on new tasks and/or initiative new policy instruments, as the example of the EU shows (see Table 1 for coding examples). We code policy responses on a six-point scale, with IOs that have not responded at all to COVID-19 coded as zero and IOs that have only issued a discursive response as low (1). IOs that are fulfilling their established tasks or/and use established policy instruments are coded as low-medium (2) and medium (3), and as high (4) and very high (5) if they are taking on new tasks or/and have initiated new policy instruments (see Table A and B, Appendix for full coding of all IOs; we also perform a robustness check with a three-point scale: low, medium, high, see Table C, Appendix). 
Table 1. Examples of coding for six IOs by policy instruments and scope

\begin{tabular}{|c|c|c|c|c|c|}
\hline IO name & Policy instruments & Coding & Policy scope & Coding & Scale \\
\hline $\begin{array}{l}\text { European } \\
\text { Union (EU) }\end{array}$ & $\begin{array}{l}\text {-Temporary unemployment scheme } \\
\text {-Recovery fund financed through } \\
\text { joint debt } \\
\text {-European Stability Mechanism } \\
\text { for health purposes }\end{array}$ & $\begin{array}{l}\text { New policy } \\
\text { instruments }\end{array}$ & $\begin{array}{l}\text {-Health } \\
\text {-Social policy } \\
\text {-Border } \\
\text { management } \\
\text {-Finance }\end{array}$ & Scope expansion & $\begin{array}{l}\text { Very high } \\
(=5)\end{array}$ \\
\hline $\begin{array}{l}\text { International } \\
\text { Monetary } \\
\text { Fund (IMF) }\end{array}$ & $\begin{array}{l}\text {-Initiation of new short-term } \\
\text { liquidity lines } \\
\text {-Repurposing of existing funds } \\
\text { for emergency relief }\end{array}$ & $\begin{array}{l}\text { New policy } \\
\text { instruments }\end{array}$ & $\begin{array}{l}\text {-Trade } \\
\text {-Finance }\end{array}$ & Existing scope & High $(=4)$ \\
\hline $\begin{array}{l}\text { Southern } \\
\text { African } \\
\text { Development } \\
\text { Community } \\
\text { (SADC) }\end{array}$ & $\begin{array}{l}\text {-Harmonization of Health Guidelines } \\
\text {-Coordination of trading rules for } \\
\text { cross-border transports } \\
\text {-Coordination with other global } \\
\text { and regional IOs } \\
\text {-Negotiations with India on } \\
\text { preferential trading in medical } \\
\text { supplies }\end{array}$ & $\begin{array}{l}\text { Existing policy } \\
\text { instruments }\end{array}$ & $\begin{array}{l}\text {-Health } \\
\text {-Trade } \\
\text {-Political } \\
\text { coordination }\end{array}$ & Existing scope & $\begin{array}{l}\text { Medium } \\
(=3)\end{array}$ \\
\hline $\begin{array}{l}\text { World Trade } \\
\text { Organization } \\
\text { (WTO) }\end{array}$ & $\begin{array}{l}\text {-Joint statement with IMF } \\
\text {-Limited reporting on international } \\
\text { trade flows }\end{array}$ & $\begin{array}{l}\text { Limited use of } \\
\text { existing policy } \\
\text { instruments }\end{array}$ & $\begin{array}{l}\text { Trade } \\
\text { (Monitoring) }\end{array}$ & Existing scope & $\begin{array}{l}\text { Low-Medium } \\
\qquad(=2)\end{array}$ \\
\hline $\begin{array}{l}\text { Central African } \\
\text { Economic and } \\
\text { Monetary Union } \\
\text { (CEMAC) }\end{array}$ & Statement by Secretary General & $\begin{array}{c}\text { Discursive } \\
\text { response }\end{array}$ & $\begin{array}{l}\text { No activity } \\
\text { reported }\end{array}$ & Not applicable & $\operatorname{Low}(=1)$ \\
\hline $\begin{array}{l}\text { International } \\
\text { Whaling } \\
\text { Commission } \\
\text { (IWhale) }\end{array}$ & No response & No response & $\begin{array}{l}\text { No activity } \\
\text { reported }\end{array}$ & Not applicable & $\begin{array}{l}\text { No response } \\
(=0)\end{array}$ \\
\hline
\end{tabular}

We have coded policy responses for all IOs included in the Measuring International Authority (MIA) dataset by Hooghe et al. (2017). These are the 78 politically most relevant IOs since $1950 .^{2}$ To code policy responses, we have consulted the websites of all IOs to gather information on their activities since the start of the pandemic in March 2020 until the end of the study period in June 2020. We observe that most 10 responses were formulated during April and early May and consider that after June 2020 the initial window of opportunity had passed. Many IOs obviously remain active in dealing with COVID-19, but the critical juncture which could set IOs on new paths is over. Relying on online data gathering might not cover all daily practices. Nevertheless, it helps to capture a snapshot of 10 capacity to communicate actions online, and thus also serves as a proxy to measure how well IOs are able to keep up policy functions.

We find that 22 IOs did not respond to COVID-19 at all during the first wave or only issued statements about the importance of the pandemic for their policy field (coded 0 or 1) (see Figure 1). While many of these are task-specific IOs, which we would not necessarily expect to be heavily affected by COVID-19 (e.g. the International Whaling Commission), there are several economic and trading IOs (e.g. International Coffee Board) as well as regional organizations (e.g. CEMAC) that are dealing with policy fields directly hit by COVID-19.

The majority of IOs (35) used their existing policy instruments and/or stayed within their existing scope to deal with the challenges (coded 2 or 3). They collected data, offered webinars, or coordinated between member states. An example is the Universal Postal Union (UPU), which had to deal with the fact that international postal services were heavily disrupted. In May 2020, only one-in-two postal items reached their international destination due to the cancellation of passenger flights (Universal Postal Union, 2020). The response of the UPU largely focused on providing analysis and expertise, sharing best practices, and initiating small projects such as delivering personal protective equipment to United Nations (UN) field operations. 
Figure 1. Variation in scope and policy instrument expansion by staff size.

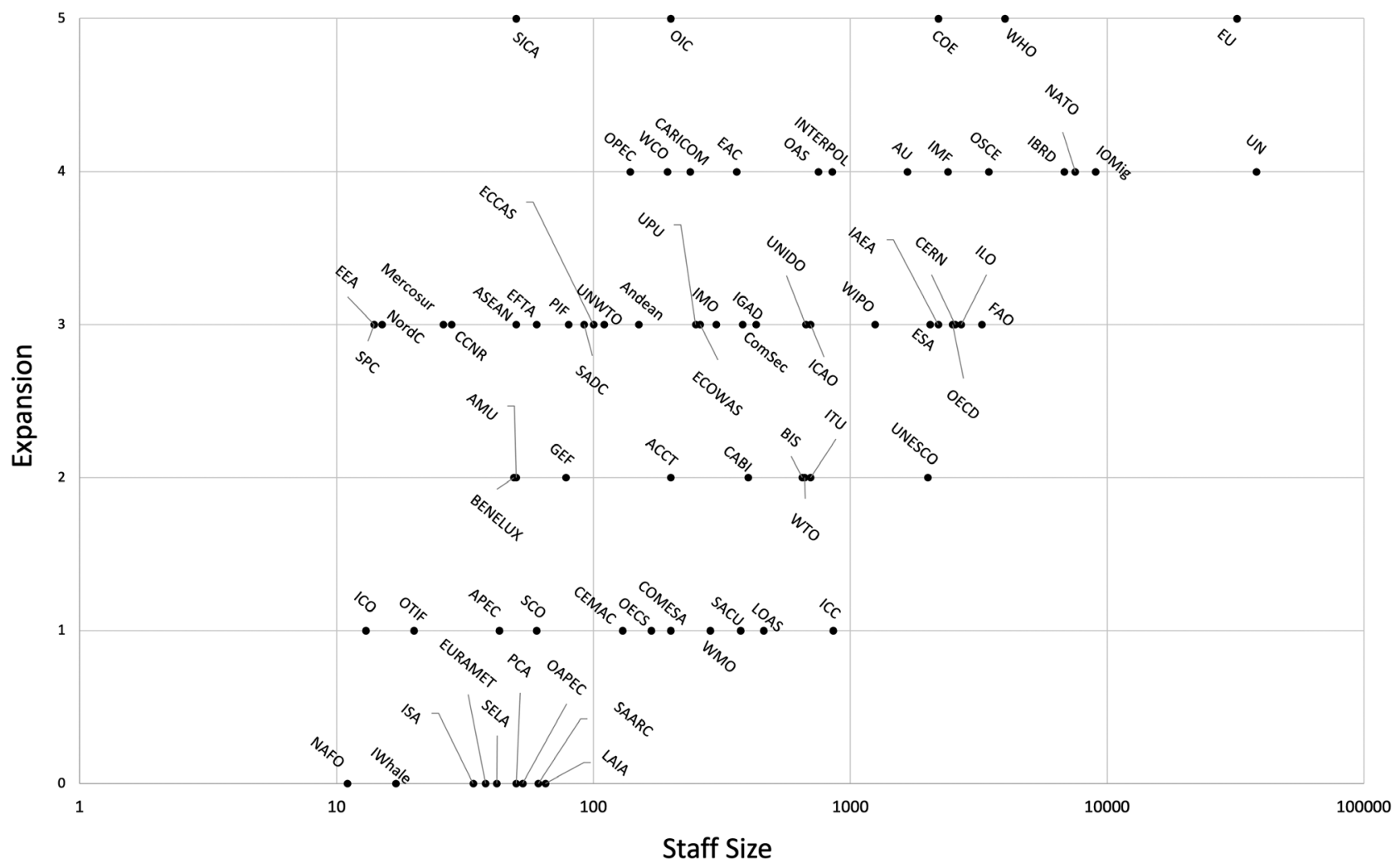

Finally, we found 18 IOs to venture into new tasks or initiate new policy instruments (coded 4 or 5). The Organization for Security and Co-operation in Europe (OSCE) started to provide humanitarian aid. The International Monetary Fund (IMF) initiated and repurposed a number of funding instruments to support least developed countries and provided short-term liquidity lines. Some IOs even used the crisis to propose some potentially far-reaching changes: the EU agreed to joint debt, the WHO has taken up global supply change management in coordination with the World Food Programme (WFP), and the Council of Europe (CoE) ventured into health policy by financing liquidity shortages. The CoE also used the COVID-19 crisis to reposition itself, through a public relations offensive, as the focal institution for human rights in Europe, with a number of initiatives surrounding the organization and legality of cyber justice.

IOs have responded differently to COVID-19. Some have barely engaged at all, whereas others have seen an opportunity in this crisis. The remainder of the article seeks to explain such variation. It is, in this respect, important to reiterate that our dependent variable should not be equated with effectiveness of response. Some IOs have actually been heavily contested for their slow or inadequate initial response. The EU and $\mathrm{WHO}$ are perhaps the most prominent examples of IOs of which many people expected more (Johnson, 2020). An initial lack of effectiveness may also drive IOs into new territory. As previous health crises show, the WHO ended up with expanded authority in the wake of the SARS and Ebola crisis exactly as a result of identified shortcomings (Kreuder-Sonnen, 2019). A demand for increased authority of IOs may also result in contestation. EU member states, for instance, fought heavily over the allocation of funds and the issue of joint debts, even if the EU eventually came out with innovative funding instruments, a larger budget, and an increased policy scope (Wolff and Ladi, 2020).

\section{COVID-19, institutional design, and policy responses}

This article argues that variation in institutional design of IOs conditions the likelihood to be able to respond and adapt to unforeseen crises such as COVID-19 (Hooghe et al., 2019; Koremenos et al., 2001). This section puts forward two sets of hypotheses on the authority and the bureaucratic capacity of IOs. It posits that IOs with more authority and bureaucratic capacity are better able to respond to exogenous shocks and have the ability to strategically use the crisis to their advantage.

As already noted in the introduction, much of the initial commentary has pointed out how COVID-19 further undermines the liberal international order (Greitens, 2020; Kenwick and Simmons, 2020). Various observers noted that COVID-19 is the first international crisis since the end of the Cold War where the United States does not play a coordinating role (Norrlöf, 2020). Kahl and Wright (2021, title) talk 
about the 'end of the old international order.' China seems to accelerate its development as a great power by embarking on 'mask diplomacy' and tightening its hold on Hong Kong (Mahbubani, 2020). Such geopolitics also caused gridlock within IOs with notably the WHO losing funding from the United States and being accused of China-bias. Many states furthermore pursued domestic strategies, such as closing borders, with nationalization coming at the expense of multilateral cooperation (Bouckaert et al., 2020; Ferhani and Rushton, 2020; Johnson, 2020).

While COVID-19 presents a challenge to the liberal international order, we also know that cross-border problems (with COVID-19 as a case in point) often provide impetus for (renewed) cooperation (Rittberger et al., 2019). Indeed, the WHO and its predecessors were originally established precisely because 'diseases do not stop at borders'. It is also well-known that IOs regularly benefit from crises, because established orders become fluid when the stakes are high and rapid response is imperative (Kreuder-Sonnen, 2019; Olsson and Verbeek, 2018; Schimmelfennig, 2018; Stone, 2011). Crises also often highlight the previous shortcomings of IOs resulting in more delegation of authority (Jones et al., 2016). As one of the founding fathers of the EU famously said, 'Europe will be forged in crises, and will be the sum of the solutions adopted for those crises' (Monnet, 1978, p. 417). From this perspective, it is not surprising that some IOs have used COVID-19 to expand their scope and policy instruments.

To explain the ability of IOs to benefit from exogenous shocks in the short-term requires us to pay attention to institutional design. The institutions of IOs, of course, evolve over time. Yet in the short-term, they condition the likelihood of IOs to be able to respond and adapt to unforeseen circumstances and crises. When COVID-19 hit, IOs had to craft responses in line with the institutions they had at their disposal. While there are potentially many relevant institutional design features, the two key questions are whether 10 had sufficient authority to formulate policy responses, including those expanding the scope of cooperation and proposing new policy instruments, and the bureaucratic capacity to do so in a strategic and credible manner.

The authority of IOs is important in times of crisis because it determines where and how policy responses and decisions are made. This institutional setting, in turn, provides the opportunity structure which affects whether IOs can cope with or even benefit from COVID-19 (van Hecke et al., 2021). Authority consists of two dimensions: the delegation and pooling of sovereignty (Hooghe et al., 2017). Delegation involves 'a conditional grant of authority by member states to an independent body' (Hooghe et al., 2017, p. 21), such as a secretariat which may set the decision-making agenda by proposing policies or take day-to-day decisions. It is likely that IOs with high degrees of delegation will be better able to respond to crises. First, if secretariats have some decision authority, they can make emergency decisions in the interest of the continued operations of the 10 even if member states in the executive organs have difficulty reaching consensus. Second, if secretariats have agenda-shaping powers they can proactively propose responses and new policy initiatives.

Pooling concerns 'joint decision making among the principals themselves' (Hooghe and Marks, 2015, p. 307) and involves, amongst others, the decision-rule and whether member states have vetoes, particularly in the executive organs. Other things being equal, majority-voting not only helps to speed up decision-making, which is critical in crises, it also avoids gridlock due to opposing veto-players (Hale et al., 2013; Tsebelis, 2002). If IOs have high degrees of authority, either through the delegation or pooling of sovereignty, they are more likely to be in position to cope with crises or actually use crises as opportunities to adapt policies. Since there is a trade-off between the pooling and delegation of sovereignty (Hooghe and Marks, 2015), as IOs with a large membership typically pool rather than delegate sovereignty, authority is tested through two separate hypotheses:

H1a: IOs with higher delegated sovereignty will more likely expand their scope and policy instruments during crises.

H1b: IOs with higher pooled sovereignty will more likely expand their scope and policy instruments during crises.

IOs should also have the bureaucratic capacity to respond to crises (Bauer and Ege, 2016; Heldt and Schmidtke, 2017). With COVID-19, meetings were cancelled, and officials have been working from home. It is therefore not guaranteed that IOs have the ability to formulate adequate policy responses. In line with advances on international public administration (e.g. Bauer et al., 2017; Knill and Bauer, 2016), this article tests three aspects of bureaucratic capacity: staff, budget, and leadership.

First, the presence of a substantial secretariat will more likely allow IOs to benefit from crises. IOs with substantial staff resources may be able to reassign staff members to work on crisis response. They may also have strong in-house expertise which they can use to pursue organizational interests (Barnett and Finnemore, 2004; Bauer and Ege, 2016; Eckhard and Ege, 2016; Hawkins et al., 2006). While IOs with large bureaucracies may experience institutional pathology and not be flexible enough to grasp opportunities (Barnett and Finnemore, 2004), Gray (2018) finds that quality staff is critical for the vitality of IOs and Johnson (2014) shows how secretariat staff act opportunistically when designing new institutions. While some IOs - such as the EU, UN, and WHO - have substantial secretariat resources, many of the 75 major IOs have in fact rather limited staffs often below 50 officials (Debre and Dijkstra, 2021). If there are very few actual policy officers, they may simply be overwhelmed with guaranteeing the continuation of operations and may not have the ability to proactively propose new policy instruments.

Second, available budget is also important. IOs vary significantly with regard to available funding, with some regulatory IOs (e.g. World Trade Organization) mostly having 
administrative budgets and operational IOs (e.g. World Bank) having sizeable funds (Rittberger et al., 2019). Due to institutional rules of IOs and lengthy budgetary cycles (Patz and Goetz, 2019), it is much more likely that IOs which already have substantial funds and experience in disbursing them will be treated as focal institutions in COVID-19 response (see also Ege and Bauer, 2017; Goetz and Patz, 2017). They might free up funds, use flexibility rules to reallocate funds across policies, or set up new funding instruments. In light of the available data (see further below), we limit the analysis to overall budgets of IOs. While a more elaborate conceptualization of budgetary politics in crises is worthwhile for further studies, it is also reasonable that IOs which do not have substantial budgets are not likely to get them, in the short-term, simply for the purpose of responding to COVID-19.

Finally, it is important to pay attention to leadership which is critical in times of crises (e.g. Boin et al., 2016). While there are various determinants of public leadership, it seems that seniority and experience are particularly relevant for IOs in times of crises (Kille and Scully, 2003; Young, 1991). It is more likely that more senior and experienced politicians will identify the opportunities in crises rather than solely focus on continuity of operations. Officials with experience at the highest level may also be more used to working across organizational boundaries and overcoming formal and institutional constraints (Hall and Woods, 2018). Finally, senior politicians are more likely to have serious international networks and close connections to national capitals.

This leads to the following set of hypotheses:

H2a: IOs with a larger secretariat will more likely expand their scope and policy instruments of IOs during crises.

H2b: IOs with a larger budget will more likely expand their scope and policy instruments during crises.

H2c: IOs with a senior leader at the helm of the secretariat will more likely expand their scope and policy instruments during crises.

\section{Research design}

This article tests these institutional hypotheses through an ordered logistic regression analysis of policy responses by 75 major IOs. The dependent variable has already been conceptualized and operationalized above and is measured on a six-point scale. This section discusses the independent and control variables.

To test hypothesis $1 \mathrm{a}$ and $1 \mathrm{~b}$, we use the MIA dataset by Hooghe et al. (2017) on delegation and pooling. Their extensive dataset includes aggregate measures of both concepts as well as scores for a number of sub-dimensions. As a starting point, we include the two aggregated variables to measure the degree of decision-making authority conferred to IO bodies (delegation) and the degree of joint decision-making in the collective IO body (pooling). We use the values for the last available year in the dataset (2010). Since pooling and delegation are relatively stable measures and have not drastically changed between 2005 and 2010 (Hooghe et al., 2019), we are confident that the values remain valid representations of 10 authority in 2020.

In addition to both aggregate measures of delegation and pooling, we include four variables from Hooghe et al. (2017) on sub-dimensions: delbudget and delpolicy measure the extent to which budgetary allocation and agenda-setting powers have been delegated to the secretariat or executive bodies. In case of delegated agenda-setting powers, IOs may be able to suggest new initiatives, whereas budgetary powers should allow for more discretion in allocating funding to COVID-19 responses. For pooling, we similarly include the sub-dimensions of poolbudget and poolpolicy, which measure the degree to which decision-making is jointly exercised with regard to policy-making and budgetary matters. Majority-voting in IOs should, in this respect, allow more easily for scope expansion and new policy instruments.

We test hypotheses $2 a-c$ on the basis of the readily available data. To measure secretariat size, we use data on permanent staff provided by the Yearbook of International Organizations for the last reported year and include the logged number of staff (staffsize) to deal with the skewed distribution. Where the Yearbook does not provide data, we have done additional online research on the websites of the organizations. To measure budget size (budget), we have collected data on the budgets of IOs in the fiscal year 20192020 from annual reports. Ideally, we would have included variables for the type of budgetary funding as well as the flexibility of budgetary rules during crisis situations. These are unfortunately not available for these 75 IOs. Indeed, even exact budget numbers are not available for 29 of the 75 IOs. We therefore decided to measure budget in categorical form, differentiating between IOs with small $(<$ US\$100 million), medium (100 million to 1 billion) and large budgets ( $>1$ billion). We infer budget size for those IOs that do not provide exact numbers for 2019 from reporting in previous years or descriptions in secondary literature. As robustness check, we also included a variable using exact budget numbers (in US\$million, logged), budget_est, with estimations for missing values based on the average budgets of all IOs in the reference category (Table D, Appendix). Finally, we include a variable measuring type of leadership to differentiate if the head of secretariat (Secretary General or Director General) has previous high-level political experience (President/Prime Minister/Vice/Foreign Minister or Secretary General of another $\mathrm{IO}$ ).

We include several control variables. To measure the relevance of COVID-19 for the 75 different IOs, we include the aggregated number of COVID-19 cases (logged) of all 10 member states by 31 March 2020 as compiled by Johns Hopkins University. We expect that IOs whose members were particularly badly affected by COVID-19 at the start of the pandemic will feel more pressure to respond to the exogenous shock. In addition, we include a control variable policy field (Hooghe et al. 2017), to account for the fact that 
IOs dealing with health, economics, and finance, as well as border management and migration issues will be most affected in their work and therefore also more likely to respond. While COVID-19 is a challenge for most IOs and cuts across policy fields, from education to postal delivery, it is nevertheless important to control for those policies that caused most challenges.

In addition to the differential impact of COVID-19, we control for several additional design features. First, we control for policy scope of IOs. Hooghe et al. (2019) convincingly distinguish between task-specific and general purpose IOs, arguing that the scope of general purpose IOs is likely to expand over time, while the scope of task-specific IOs remains relatively fixed. A general purpose $I O$, such as the $\mathrm{EU}$, might become active in health policy over time, whereas the International Criminal Court is unlikely to do so. Second, we control for the number of member states (logged) (Pevehouse et al., 2020) with the expectation that IOs with a large membership will have more difficulty expanding policies in light of COVID-19. Third, we include a dichotomous variable power politics indicating whether both China and the United States are members of an IO. Since many commentators have pointed at American-Chinese rivalry, we would expect IOs that include both countries as members to be unable to develop ambitious policy responses.

\section{Analysis and discussion}

We use ordered logit models (McCullagh, 1980) with robust standard errors due to the ordinal measurement of our dependent variable. The analysis presented in Table 2 reports results for five models. Model (1) shows results for hypotheses $1 \mathrm{a}$ and $1 \mathrm{~b}$ on the effects of pooling and delegation of authority on policy responses, model (2) uses the sub-dimensions for pooling and delegation, and model (3) reports results for Hypotheses $2 \mathrm{a}, \mathrm{b}$, and $\mathrm{c}$ about the effect of bureaucratic capacity, namely size of staff, budget, and leadership. Model (4) is a fully saturated model and Model 5 tests an interaction effect between staff and authority. ${ }^{3}$ Additionally, we report results of these five models with a differently scaled dependent variable in the Appendix (Table C) to test if results hold with collapsed categories (low $=0$ and 1 , medium $=2$ and 3 , high $=4$ and 5), thereby increasing the number of observations for each category. The results remain largely the same.

The models reveal interesting results. First, size of staff is one of the most important predictors to explain policy responses at the 0.05 significance level. In fact, an IO with ten times more staff has a 1.6 times higher probability of responding to the crisis in some way ( $d v=1$ to 5 ) instead of shutting down and doing nothing $(d v=0)$. The left-hand side of Figure 2 explores the magnitude of this effect for relative probabilities that an 10 exhibits low, medium, and very high levels of scope and policy instrument expansion. Substantively, they show that increasing staff size has a large effect on the probability that an IO has expanded its policy scope or instruments, with large IOs being highly unlikely to barely engage with COVID-19 at all. ${ }^{4}$ We can thus accept
Hypothesis 2a: IOs with a larger secretariat will more likely expand their scope and policy instruments during crises.

In contrast, neither budget nor leadership seniority are significant predictors, leading us to reject $\mathrm{H} 2 \mathrm{~b}$ and $\mathrm{H} 2 \mathrm{c}$. However, when including real budgetary data with estimates for missing values (Table D, Appendix), budget turns significant at the 0.1 significance level, pointing at the potential relevance of budget as a predictor of scope and instrument expansion. We also have to reject $\mathrm{H} 1 \mathrm{a}$ and $\mathrm{H} 1 \mathrm{~b}$ on the effect of pooling and delegation. However, model (2) shows that this is not true for the more specific variable that measures power-setting agenda with regard to policy making, which is significant at the 0.1 level. While we have to be careful with our conclusions at these significance levels, given the relatively small sample-size we think it is reasonable to highlight these results. The right-hand side of Figure 2 further exemplifies these findings: while the odds of being in the low category decrease with increasing policy agenda-setting authority and are relatively stable for the medium category (continuity of functions), the odds increase for the very high category (exploit crisis as opportunity). This positive effect of delegated policy agenda-setting power on the probability of scope and instrument expansion is even stronger if we collapse the categories of the dependent variable to three (see Table C, Model 2, Appendix).

Finally, model (5) tests to what extent larger bureaucracies with more delegated authority are more likely to expand their scope and policy instruments. Arguably, bureaucracies will only be able to move forward if they have at least some delegated authority to set the agenda and push for their proposals. However, the interaction effect itself is not significant, while the main effect of staff size remains highly significant. This could indicate that large bureaucracies are relevant during the COVID-19 crisis even if they do not have the formal power of agenda-setting. The interaction effect is significant in the alternative model with collapsed categories for the dependent variable (see Table C, Model 5, Appendix). Graphing the interaction reveals that the marginal effect of increasing policy agenda-setting authority is only significant for very large bureaucracies (with staff above roughly 400). The marginal effect of policy-agenda power on the probability of high scope and instrument expansion ( $d v=$ high) decreases with growing staff size, while it increases for the probability of being able to offer continuation of functions ( $\mathrm{dv}=$ medium). Thus, model (5) in Table C confirms that IOs with larger bureaucracies might not necessarily need policy agenda-setting authority to push for innovations, but that they may profit from it when it comes to keeping up shop during crisis.

These findings merit discussion. It is surprising that $\mathrm{H} 1 \mathrm{a}$ and $\mathrm{H} 1 \mathrm{~b}$ on delegated and pooled sovereignty are not significant and this indirectly challenges the keynote work by Hooghe et al. (2019). As aggregate measures, however, these concepts include a number of sub-dimensions that are not necessarily important in crisis situations with a short-term time horizon. As noted above, formal authority is important as it determines where and how policy responses 
Table 2. Determinants of policy responses

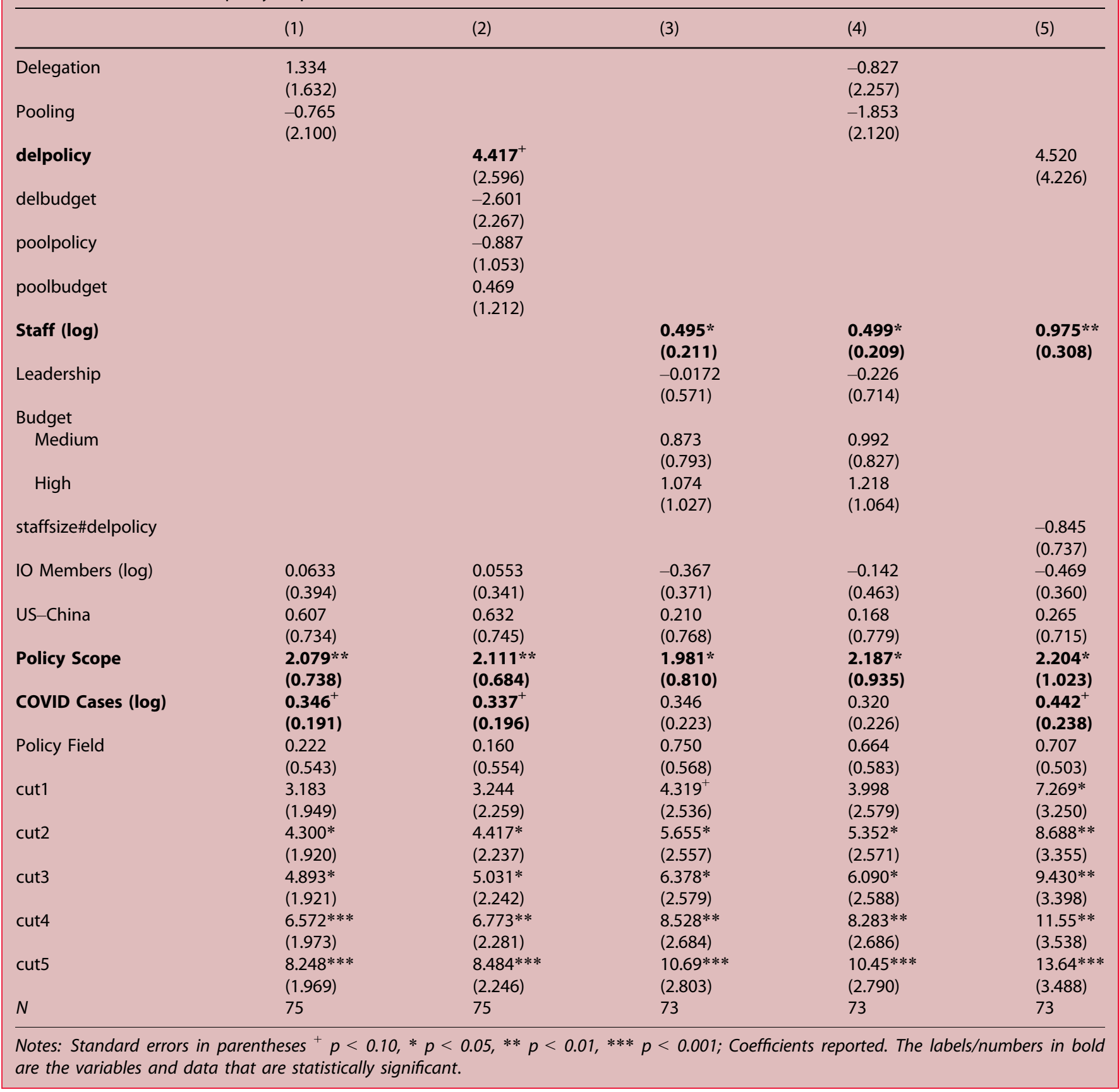

and decisions are made. At the same time, we also know that when the stakes are high, informal modes of governance may prevail (Stone, 2011) over the formal rules which are so central in the work of Hooghe et al. (2019). This may also help to explain the significance of secretariat staff. Ultimately, secretariats provide most continuity to IOs, as member states may not meet in the plenary and executive organs on a daily basis. In fact, the pandemic has even forced many IOs to postpone their regular annual plenary meetings, so many of the short-term decisions were taken by 10 bureaucrats or only had to pass through executive committees. As such, secretariats are the ones that need to deal with crises and if they have substantial expertise, they are even more likely to be leading in formulating policy responses.

That $\mathrm{H} 2 \mathrm{a}$ is confirmed shows, once more, the importance of secretariat staff in the engine room of IOs. It also confirms bureaucratic theories that portray secretariat officials as opportunistic agents (Hawkins et al., 2006). At the same time, the adaptability of large bureaucracies is not a given (Barnett and Finnemore, 2004) and IO secretariats still need to work in tandem with key member states to actually achieve desired change in the long run (Dijkstra, 2017; Eckhard et al., 2019). These conflicting dynamics we have also 
Figure 2. Predictive margins by size of staff (left) and delegated policy making authority (right) at low, medium, and very high levels of expansion in scope and policy instruments (with $90 \%$ confidence interval)
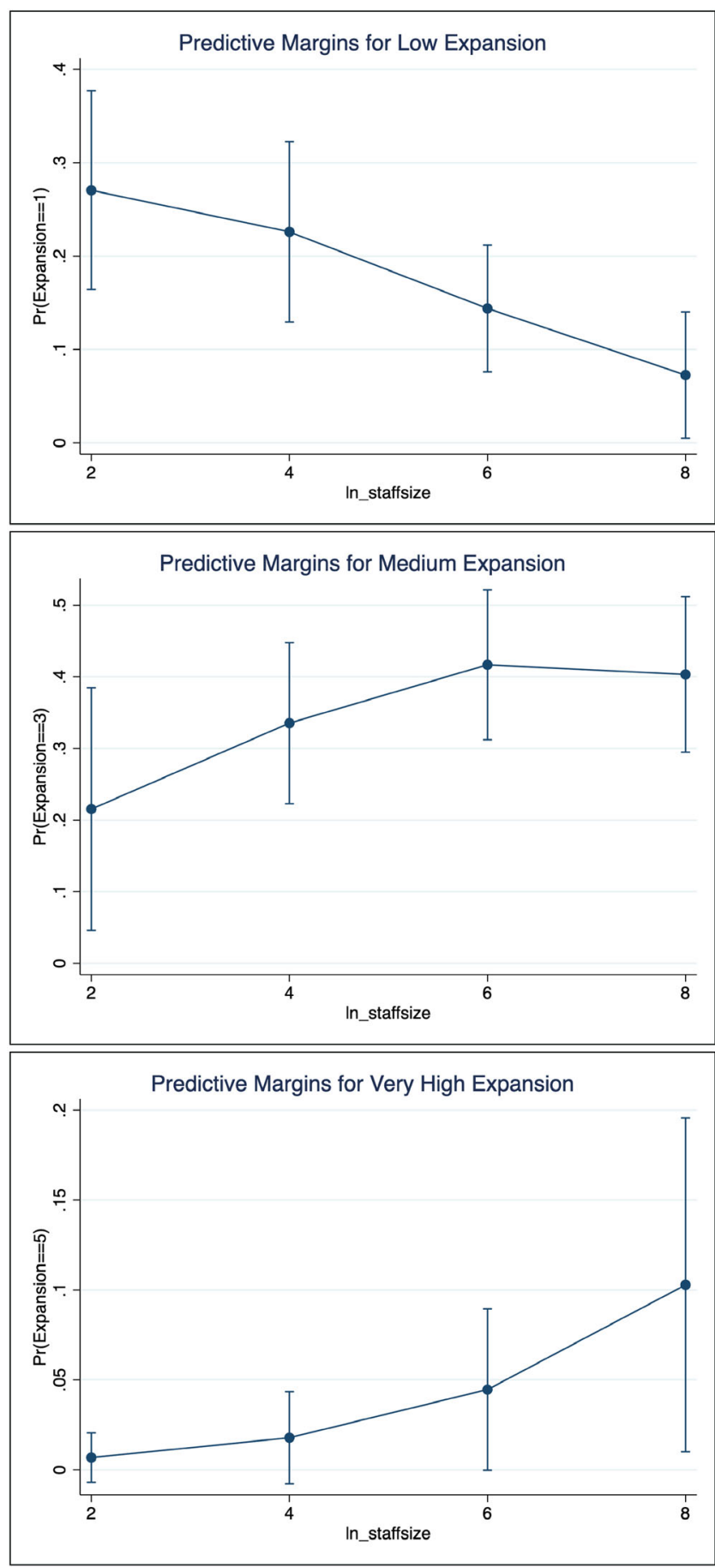

seen empirically, for instance, in the case of the EU. The initial response by the European Commission to COVID-19 was slow. A leading Member of the European Parliament wrote an op-ed entitled 'Avanti, von der Leyen!' (Verhofstadt, 2020) and Commission President Von der Leyen even issued a 'heartfelt apology' to Italy for the slow EU response (BBC, 2020). Afterwards, however, the European Commission fully
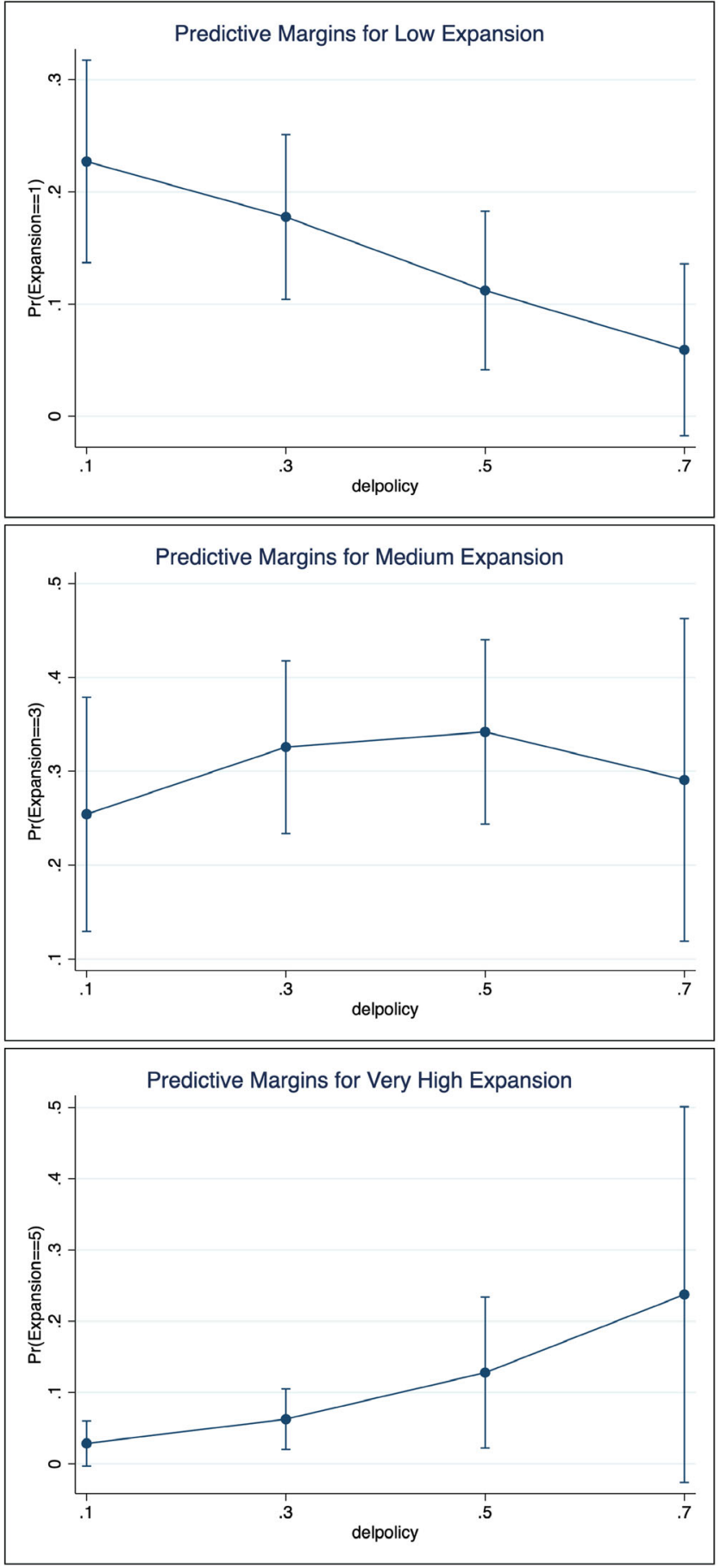

engaged, not just to tackle immediate health and economic challenges, but also to use COVID-19 and the new recovery fund of 750bn euro to promote previous Commission priorities such as climate change, digitalization, and research.

$\mathrm{H} 2 \mathrm{~b}$ on budget and $\mathrm{H} 2 \mathrm{c}$ on leadership were not confirmed. It is, however, important to stress the lack of detailed cross-sectional data on bureaucratic capacity. While 
strong data now exist on pooling and delegation of sovereignty (Hooghe et al., 2017), the operationalization of budgets and leadership capacity (and even staff size) is more limited. In fact, results from robustness checks reported in Table $D$ in the Appendix that use more fine-grained data on IO budgets show that budgetary capacity could in fact be a significant predictor for the ability of IOs to profit from crisis. We know from scholarship on the resourcing of IOs that the idiosyncrasies of individual IOs matter beyond overall budget data: whether IOs can rely on core funding in the regular budget or voluntary funding by donors, the extent to which funding is earmarked, and what budgetary flexibility is available (Goetz and Patz, 2017; Graham, 2015, 2017; Patz and Goetz, 2019). A similar caveat also applies for $\mathrm{H} 2 \mathrm{C}$ on leadership. Our operationalization is limited, and it is not always a priori clear whether the previous background of heads of secretariats determines leadership abilities during crises.

Qualitative evidence provides further support for the potential relevance of these variables. The WTO (coded as medium-low) experienced a leadership crisis with its DirectorGeneral stepping down in the middle of the first wave. The United Nations Educational, Scientific and Cultural Organization (UNESCO) (also medium-low) was marred by continuous budgetary restraints over recent years, which may have prevented it from the development of more innovative solutions for the heavily affected policy domain of education. These findings thus also further underline the need for cross-sectional data gathering on the bureaucratic capacity of IOs.

The control variables furthermore deserve attention. The number of COVID-19 cases and the policy scope of IOs are significant predictors of the probability of scope expansion during the pandemic. IOs that are active in regions with high initial numbers of cases were more likely to not only provide a continuity of functions, but also to come up with innovative instruments and take on new tasks. Likewise, general purpose IOs are also more likely to expand their scopes and instruments which fits with expectations that task-specific IOs have more stable policy portfolios (Hooghe et al., 2019). Surprisingly, policy field is not a significant predictor, despite our expectation that IOs in policy fields such as health, border management, or trade, would be most heavily affected by the pandemic. The findings suggest that exogenous shocks can be a real window of opportunity for nearly all IOs to branch out and take on new tasks.

Finally, the finding that geopolitics between the United States and China, measured in terms of both countries being a member of an IO, is not significant is also worth discussing. First, we have used quite a crude indicator for geopolitical contestation. At the same time, we see considerable variation in some of the geopolitically contested IOs. While the WHO was heavily affected by geopolitics, it has remained clearly the focal point for global health. Another example is the UN Security Council, which only managed to declare COVID-19 a threat to international peace and security on 1 July 2020, whereas much of the rest of the UN organization had responded quicker. It is, in this respect, also worth pointing out that many of the plenary and executive bodies do not continuously meet and China and the United States may not have had the opportunity to actually block the implementation of policy initiatives. Similarly, much of 10 day-to-day policy actually takes place outside the realm of great power politics, and it is up to the bureaucratic staff of an institution to take the lead when it comes to emergency politics.

\section{Conclusions}

Many observers have noted that COVID-19 is yet another nail in the coffin of the liberal international order. At the same time, this article has argued that cross-border crises such as COVID-19 can present IOs with windows of opportunity to expand their scope and develop new policy instruments. It indeed shows that there is variation between how IOs have responded to COVID-19: 22 IOs have hardly engaged with COVID-19, 35 provide some continuity of operations and use existing instruments, and 18 IOs have expanded their scope and policy instruments. We find that the bureaucratic capacity of IOs (staff in secretariat) is significant to explain this variation, and to a lesser extent also the delegation of agenda-setting authority. Furthermore, as previously found, this article also shows that general purpose IOs can more easily expand their scope than task-specific IOs (Hooghe et al., 2019). And there is also some evidence that a higher number of COVID-19 cases among the membership triggers a stronger response.

Significantly, we find that bureaucracies might be able to push their agenda even when they are lacking the formal authority to do so. When 10 bureaucrats manage to use crisis moments as windows of opportunities to expand their scope and instruments, plenary bodies might well follow suit later on to legalize these practices and thus equip the IO with more authority (Jones et al., 2016; Kreuder-Sonnen, 2019). In this respect, it will also be important to study the initial timing of IO policy responses to COVID-19. Academic literature has highlighted the role of timing in public policymaking (e.g. Agné, 2016; Eckhard et al., 2019; Howlett and Goetz, 2014), but so far, we know little about the effects of timing of policy responses on trajectories of institutional change. This is all the more important considering potential first-mover advantages.

The current COVID-19 crisis presents a clear test case to take stock of the current state of liberal international order. Just as Drezner (2014) claimed that 'the system worked' during the previous economic and financial crisis, this article shows that the large majority of IOs manage to continue their operations and some even gained from COVID-19 in terms of policy scope and instruments. The effectiveness of IO response to COVID-19 can be debated, but in terms of institutional change some IOs may be moving up and not down. The fact that many IOs as bastions of multilateralism are still standing raises questions about whether we are indeed seeing a crisis of liberal international order or within the liberal international order (Eilstrup-Sangiovanni and Hofmann, 2020). We need to wait for the longer-term impact on COVID-19, but if IOs show resilience during a cross- 
border crisis for which they were developed in the first place, their future is not necessarily bleak.

\section{Notes}

1. We would like to thank the editor and reviewers of Global Policy for their excellent supportive comments on our manuscript. The article was previously presented at the German DVPW International Section Conference Freiburg in 2020 and at the ECPR General Conference Innsbruck in 2020. We would also like to thank our ERC team members for substantive comments and Camila Kirtzman, in particular, for preparatory work. This article is part of a project that has received funding from the European Research Council (ERC) under the European Union's Horizon 2020 research and innovation programme (grant agreement No 802568). Data used in this article are available in the Appendix.

2. Due to the small number of IOs in each category, confidence intervals are relatively large in each case. However, cut-points between levels show a significant difference between categories.

3. We exclude three IOs because they are dead (COMECON, EAC1, NAFTA). NAFTA has been renegotiated in 2018 with the new agreement only taking effect on 1 June 2020 .

4. Checks for multicollinearity between independent variables reveal no significant correlations. A likelihood ratio and brant test confirm that the proportional odds assumption is not violated.

\section{Reference}

Agné, H. (2016) 'Accountability's Effect: Reaction Speed and Legitimacy in Global Governance', Global Governance, 22 (4), pp. 575-594.

Barnett, M. N. and Finnemore, M. (2004) Rules for the World: International Organizations in Global Politics. Ithaca, NY: Cornell University Press.

Bauer, M. W. and Ege, J. (2016) 'Bureaucratic Autonomy of International Organizations' Secretariats', Journal of European Public Policy, 23 (7), pp. 1019-1037.

Bauer, M. W., Knill, C. and Eckhard, S. (eds.) (2017) International Bureaucracy: Challenges and Lessons for Public Administration Research. London: Palgrave Macmillan.

Baumgartner, F. R. and Jones, B. D. (1993) Agendas and Instability in American Politics. Chicago, IL: University of Chicago Press.

BBC News. (2020) Coronavirus: EU Offers 'Heartfelt Apology' to Italy. Available from: https://www.bbc.com/news/world-europe-52311263 [Accessed 9 April 2021].

Boin, A., Stern, E. and Sundelius, B. (2016) The Politics of Crisis Management: Public Leadership under Pressure. Cambridge: Cambridge University Press.

von Borzyskowski, I. and Vabulas, F. (2019) 'Hello, Goodbye: When do States Withdraw from International Organizations?', The Review of International Organizations, 14 (2), pp. 335-366.

Bouckaert, G., Galli, D., Kuhlmann, S., Reiter, S. and van Hecke, S. (2020) 'European Coronationalism? A Hot Spot Governing a Pandemic Crisis', Public Administration Review, 80 (5), pp. 765-773.

Brooks, E. and Geyer, R. (2020) 'The Development of EU Health Policy and the Covid-19 Pandemic: Trends and Implications', Journal of European Integration, 42 (8), pp. 1057-1076.

Colgan, J. D., Keohane, R. O. and Van de Graaf, T. (2012) 'Punctuated Equilibrium in the Energy Regime Complex', The Review of International Organizations, 7 (2), pp. 117-143.

Debre, M. and Dijkstra, H. (2021) 'Institutional Design for a Post-liberal Order: Why Some International Organizations Live Longer than Others', European Journal of International Relations, 27 (1), pp. 311-339.

Dijkstra, H. (2017) 'Collusion in International Organizations. How States Benefit from the Authority of Secretariats', Global Governance, 23 (4), pp. 601-618.
Drezner, D. W. (2014) The System Worked: How the World Stopped Another Great Depression. Oxford: Oxford University Press.

Eckhard, S. and Ege, J. (2016) 'International Bureaucracies and their Influence on Policy-making: A Review of Empirical Evidence', Journal of European Public Policy, 23 (7), pp. 960-978.

Eckhard, S., Patz, R. and Schmidt, S. (2019) 'Reform Efforts, Synchronization Failure, and International Bureaucracy: The Case of the UNESCO Budget Crisis', Journal of European Public Policy, 26 (11), pp. 1639-1656.

Ege, J. and Bauer, M. W. (2017) 'How Financial Resources Affect the Autonomy of International Public Administrations', Global Policy, 8 (S5), pp. 75-84.

Eilstrup-Sangiovanni, M. and Hofmann, S. C. (2020) 'Of the Contemporary Global Order, Crisis, and Change', Journal of European Public Policy, 27 (7), pp. 1077-1089.

Ferhani, A. and Rushton, S. (2020) 'The International Health Regulations, COVID-19, and Bordering Practices: Who Gets in, What Gets out, and Who Gets Rescued?', Contemporary Security Policy, 41 (3), pp. 458477.

Gerschewski, J. (2021) 'Explanations of Institutional Change: Reflecting on a "Missing Diagonal", American Political Science Review, 115 (1), pp. 218-233.

Goetz, K. H. and Patz, R. (2017) 'Resourcing International Organizations: Resource Diversification, Organizational Differentiation, and Administrative Governance', Global Policy, 8 (S5), pp. 5-14.

Graham, E. R. (2015) 'Money and Multilateralism: How Funding Rules Constitute IO Governance', International Theory, 7 (1), pp. 162-194.

Graham, E. R. (2017) 'The Institutional Design of Funding Rules at international Organizations: Explaining the Transformation in Financing the United Nations', European Journal of International Relations, 23 (2), pp. 365-390.

Gray, J. (2018) 'Life, Death, or Zombie? The Vitality of International Organizations', International Studies Quarterly, 62 (1), pp. 1-13.

Greitens, S. C. (2020) 'Surveillance, Security, and Democracy in a PostCOVID World', International Organization, 64 (S1), pp. E169-E190.

Hale, T., Held, D. and Young, K. (2013) Gridlock: Why Global Cooperation is Failing When We Need it Most. Cambridge: Polity Press.

Hall, N. and Woods, N. (2018) 'Theorizing the Role of Executive Heads in International Organizations', European Journal of International Relations, 24 (4), pp. 865-886.

Hawkins, D. G., D. A. Lake, D. L. Nielson and M. J. Tierney (eds.) (2006) Delegation and Agency in International Organizations. Cambridge: Cambridge University Press.

Heldt, E. and Schmidtke, H. (2017) 'Measuring the Empowerment of International Organizations: The Evolution of Financial and Staff Capabilities', Global Policy, 8 (5), pp. 51-61.

Hooghe, L., Lenz, T. and Marks, G. (2019) A Theory of International Organization. Oxford: Oxford University Press.

Hooghe, L. and Marks, G. (2015) 'Delegation and Pooling in International Organizations', The Review of International Organizations, 10 (3), pp. 305-328.

Hooghe, L., Marks, G., Lenz, T., Bezuijen, J., Ceka, B. and Derderyan, S. (2017) Measuring International Authority: A Postfunctionalist Theory of Governance. Oxford: Oxford University Press.

Howlett, M. and Goetz, K. H. (2014) 'Introduction: Time, Temporality and Timescapes in Administration and Policy', International Review of Administrative Sciences, 80 (3), pp. 477-492.

Johnson, T. (2014) Organizational Progeny: Why governments are losing control over the proliferating structures of global governance. Oxford: Oxford University Press.

Johnson, T. (2020) 'Ordinary Patterns in an Extraordinary Crisis: How International Relations Makes Sense of the COVID-19 Pandemic', International Organization, 74 (S1), pp. E148-E168.

Jones, E., Kelemen, R. D. and Meunier, S. (2016) 'Failing Forward? The Euro Crisis and the Incomplete Nature of European Integration', Comparative Political Studies, 49 (7), pp. 1010-1034. 
Kahl, C. and Wright, T. (2021) Aftershocks: Pandemic Politics and the End of the Old International Order. London: St. Martin's Press.

Kenwick, M. R. and Simmons, B. A. (2020) 'Pandemic Responses as Border Politics', International Organization, 74 (S1), pp. E36-E58.

Kille, K. J. and Scully, R. M. (2003) 'Executive Heads and the Role of Intergovernmental Organizations: Expansionist Leadership in the United Nations and the European Union', Political Psychology, 24 (1), pp. $175-198$.

Knill, C. and Bauer, M. W. (2016) 'Policy-making by International Public Administrations: Concepts, Causes and Consequences', Journal of European Public Policy, 23 (7), pp. 949-959.

Koremenos, B., Lipson, C. and Snidal, D. (2001) The Rational Design of International Institutions', International Organization, 55 (4), pp. 761-799.

Kreuder-Sonnen, C. (2019) Emergency Powers of International Organizations. Oxford: Oxford University Press.

Ladi, S. and Tsarouhas, D. (2020) 'EU Economic Governance and Covid19: Policy Learning and Windows of Opportunity', Journal of European Integration, 42 (8), pp. 1041-1056.

Lundgren, M., Squatrito, T. and Tallberg, J. (2018) 'Stability and Change in International Policy-making: A Punctuated Equilibrium Approach', The Review of International Organizations, 13 (4), pp. 547-572.

Mahbubani, K. (2020) The World after Covid-19: Kishore Mahbubani on the Dawn of the Asian Century. The Economist. Available at: https:// www.economist.com/by-invitation/2020/04/20/kishore-mahbubanion-the-dawn-of-the-asian-century [Accessed 9 April 2021]

McCullagh, P. (1980) 'Regression Models for Ordinal Data', Journal of the Royal Statistical Society: Series B (Methodological), 42 (2), pp. 109-127.

Monnet, J. (1978) Jean Monnet: Memoirs. London: Collins.

Norrlöf, C. (2020a) 'Is COVID-19 the end of US Hegemony? Public Bads, Leadership Failures and Monetary Hegemony', International Affairs, 96 (5), pp. 1281-1303.

Norrlöf, C. (2020b) 'Is Covid-19 a Liberal Democratic Curse? Risks for Liberal International Order', Cambridge Review of International Affairs, 33 (5), pp. 799-813.

Olsson, E. K. and Verbeek, B. (2018) 'International Organisations and Crisis Management: Do Crises Enable or Constrain IO Autonomy?', Journal of International Relations and Development, 21 (2), pp. 275299.

Patz, R. and Goetz, K. H. (2019) Managing Money and Discord in the UN: Budgeting and Bureaucracy. Oxford: Oxford University Press.

Pevehouse, J. C., Nordstrom, T. and Warnke, K. (2020) 'Tracking Organizations in the World: The Correlates of War IGO Data, Version 3.0', Journal of Peace Research, 57 (3), pp. 492-503.

Pierson, P. (2000) 'Increasing Returns, Path Dependence, and the Study of Politics', American Political Science Review, 94 (2), pp. 251-267.

Rittberger, V., Zangl, B., Kruck, A. and Dijkstra, H. (2019) International Organization. London: Red Globe Press.
Schimmelfennig, F. (2018) 'European Integration (Theory) in Times of Crisis. A Comparison of the Euro and Schengen Crises', Journal of European Public Policy, 25 (7), pp. 969-989.

Stone, R. W. (2011) Controlling Institutions: International Organizations and the Global Economy. Cambridge: Cambridge University Press.

Tsebelis, G. (2002) Veto Players: How Political Institutions Work. Princeton, $\mathrm{NJ}$ : Princeton University Press.

Universal Postal Union. (2020) Union Postale. Available at: https://www. upu.int/UPU/media/upu/publications/Union\%20Postale/2020/revue UnionPostale_Summer2020_En_web.pdf [Accessed 9 April 2021].

van Hecke, S., Fuhr, H. and Wolfs, W. (2021) 'The Politics of Crisis Management by Regional and International Organizations in Fighting against a Global Pandemic: The Member States at a Crossroads', International Review of Administrative Sciences, 2085232098451. https://doi.org/10.1177/0020852320984516.

Verhofstadt, G. (2020) Avanti, von der Leyen! Euractiv. Available at: https://www.euractiv.com/section/future-eu/opinion/avanti-von-der-le yen/ [Accessed 9 April 2021].

Wolff, S. and Ladi, S. (2020) 'European Union Responses to the Covid-19 Pandemic: Adaptability in Times of Permanent Emergency', Journal of European Integration, 42 (8), pp. 1025-1040.

Young, O. (1991) 'Political Leadership and Regime Formation: On the Development of Institutions in International Society', International Organization, 45 (3), pp. 281-308.

Zürn, M. (2018) A Theory of Global Governance: Authority, Legitimacy, and Contestation. Oxford: Oxford University Press.

\section{Supporting Information}

Additional supporting information may be found online in the Supporting Information section at the end of the article.

Appendix S1

\section{Author Information}

Maria Josepha Debre is a postdoctoral researcher and lecturer at Potsdam University and an associate researcher in the ERC project 'Who gets to live forever?' at Maastricht University. Her research focuses on regional and international organizations and their institutional design and on the international dimension of democratization and autocratic survival.

Hylke Dijkstra is an associate professor at the Department of Political Science, Maastricht University, The Netherlands. He is the principal investigator of the project 'Who gets to live forever?' on the decline and death of international organizations funded by the European Research Council. He focuses on international organizations. 